\title{
Inbred Israeli families aid research on rare diseases
}

In small villages across Israel, some ethnic groups are known for arranging marriages between close relatives. Genetic studies of these families are shedding light on a formerly obscure subgroup of metabolic disorders.

More information could help screen for, diagnose - and perhaps treat - these poorly understood and rare disorders.

The disorders stem from abnormalities in mitochondria, organelles that power the cell's activities. "When the mitochondria are defective, the entire metabolism is flawed, everything is stuck-it's like blocking traffic at the biggest intersection next to a large city," says Orly Elpeleg, director of the Metabolic Diseases Unit at Hadassah University in Jerusalem.

Elpeleg and others are studying mitochondrial diseases in large families with a high proportion of consanguinity - marriages between close relatives, such as first cousins. The custom is common in several Israeli communities and particularly among Muslim minorities in rural areas.

"Israel is one of the best places in the world to do genetic studies because of the high consanguinity rates," Elpeleg says.

The families are a geneticist's dream: if one of their ancestors carried a certain mutation, the third-generation offspring might inherit this same mutation twice, through both the mother and father. Such double-whammies show up readily on linkage analysis, making diseasecausing genetic defects easier to find. "We don't

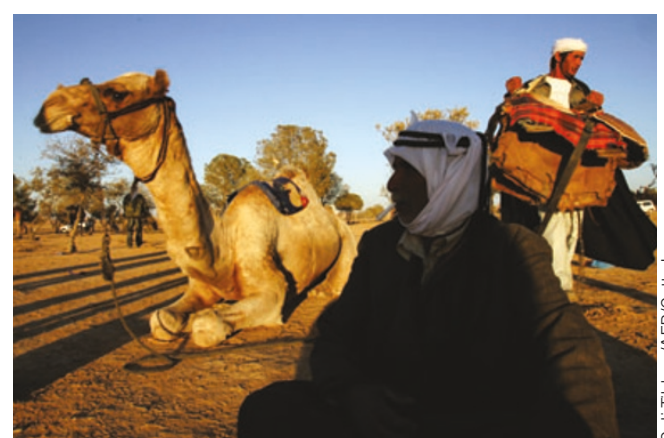

Genetic goldmine: Scientists are studying some Bedouin families to find disease-causing defects.

want people to be marrying their first cousins but if they do, it helps us find the gene," says Eric Schon, professor of genetics and development at Columbia University.

In the early 1990s, Schon discovered a subgroup of diseases, known as mitochondrial DNA depletion syndromes, in which the organelles produce little or no DNA. Most patients with the syndrome die in their first year of life.

Mitochondrial defects are notoriously difficult to diagnose because their symptoms vary greatly. In adults, about $2 \%$ of diabetes cases can be traced back to mitochondrial defects that deprive the pancreas of the energy it needs to produce insulin. Abnormalities in the organelle can also lead to kidney dysfunction, high blood pressure, hearing impairment, dementia and stroke. In children, they can cause liver failure, mental retardation and fatal muscle weakness.
The genetic defects behind mitochondrial disorders are also largely unknown because of the great number of genes involved. Although mitochondria have only 37 genes, hundreds of genes in the cell's nucleus, most of which have yet to be revealed, are needed for their regulation and maintenance. "The fact that so many genes are involved in the functioning of the mitochondria, and that each mutated gene causes its own symptoms, probably explains the baffling diversity of mitochondrial disorders," Elpeleg says.

The Israeli researchers and others have thus far identified five genes that trigger mitochondrial DNA depletion. In 2001, in collaboration with researchers at Haifa's Rambam Medical Center, Elpeleg's team identified two genes that interfere with mitochondrial DNA synthesis. Most recently, based on her work in one large Muslim-Bedouin family, Elpeleg found yet another gene that interferes with DNA synthesis through a different mechanism and causes encephalopathy, a degenerative disease of the brain.

There is no treatment yet for mitochondrial disorders, but pinpointing their genetic causes is a move in that direction, Elpeleg notes. "The mitochondria are so central to the cell that all the usual therapeutic tricks, such as bypassing or blocking this or that pathway, don't work," she says. "But if you don't know where things went wrong, how can you even start thinking about treatment?"

Luba Vikhanski, Jerusalem

\section{Growing safety concerns stir caution on gastric bypass surgery}

For the morbidly obese, the lack of effective obesity drugs has made surgery an increasingly attractive option. Bariatric surgery, in which surgeons bypass a large part of the stomach, leads to dramatic, largely permanent weight loss. Since the early 1990s, use of the procedure has grown exponentially, with an estimated 170,000 procedures expected in 2005.

Those who have the surgery lose about $60 \%$ of their excess weight on average. What's more, obesity-related conditions such as diabetes and high blood pressure improve markedly (JAMA 292, 1724-1737; 2004). The procedure costs about $\$ 25,000$, but the health benefits prompted about half of insurance companies to reimburse the expense.

In the last year, however, soaring costs and safety concerns have struck a note of caution. In October, David Zingmond and colleagues at the University of California
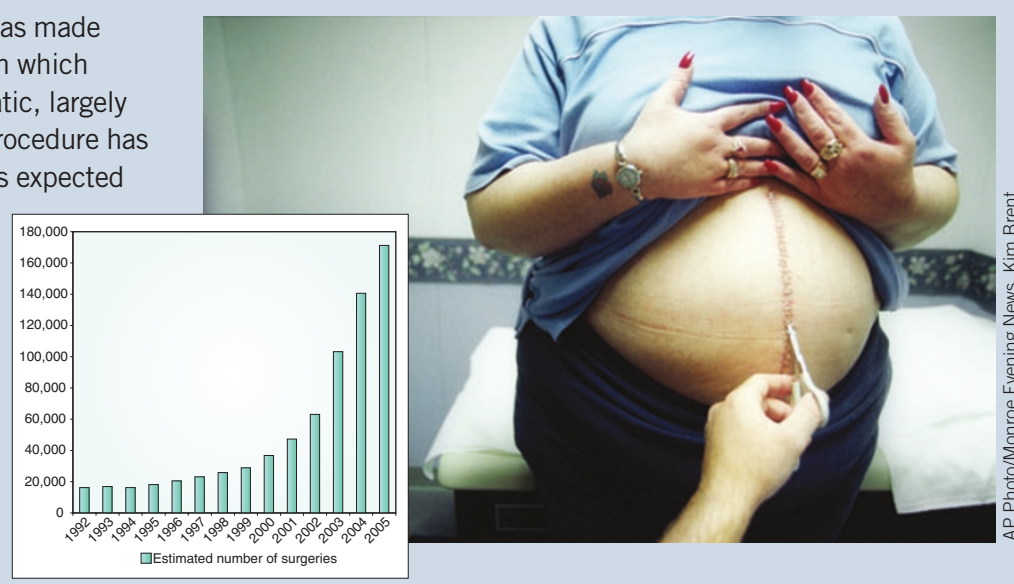

in Los Angeles reported that of 25,000 Californians who had the surgery in the past decade, $40 \%$ returned to a hospital in the three years following their surgery, most often as a result of to post-surgical complications (JAMA 294, 1918-1924; 2005).

That may signal a more favorable outlook for obesity drugs. "The managed care industry is terrified of the high costs associated with bariatric surgery," says Donny Wong, an obesity market analyst at the Massachusetts-based Decision Resources_- "terrified enough that they might start wanting to reimburse for obesity drugs."

Meredith Wadman, Washington DC 